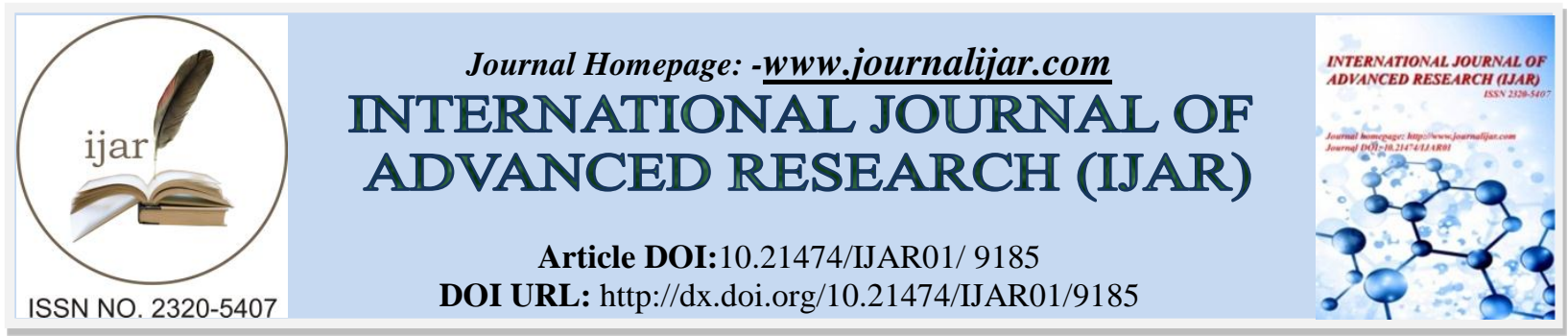

RESEARCH ARTICLE

\title{
LIVED EXISTENTIAL EXPERIENCES AMONG YOUNG ADULTS DIAGNOSED WITH CANCER: A QUALITATIVE STUDY.
}

C.Vasantha Kalyani, Suresh K. Sharma, Kusum K. And Lijumol K J.

Department of Nursing, All India Institute of Medical Sciences, Rishikesh.

\section{Manuscript Info}

\section{Manuscript History}

Received: 26 March 2019

Final Accepted: 28 April 2019

Published: May 2019

Key words:-

Cancer, quality of life, qualitative study, young adult's cancer patients.

\section{Abstract}

Background: Cancer is a major health issue which affect the quality of life of a person.

Aim: The aim of present study was to explore lived existential experiences of young adults diagnosed with cancer

Methods: The present study was a qualitative study that included 30 young adult cancer patients of age group 20- 44 years who were admitted in different Oncology units of the hospital in 2018. Review of the patients' case data sheets was done for identifying clinical variables. Qualitative data were collected by using open ended questionnaire regarding young adult's cancer patient's experiences, feeling and difficulties faced during cancer diagnosis and treatment. Results: When patient were first told about cancer diagnosis first, they feel sad. Their primary relatives were first informed about their diagnosis. Cancer was diagnosed in first stage in case of most of the patients. Cancer had affected patient's personal as well as social life completely. Majority of cancer treatment options were chemotherapy, radiation therapy and surgery and majority of them were getting chemotherapy from AIIMS, Rishikesh. Most common difficulty the patient's faced during diagnosis of cancer was financial hardship. Patient's opinion for cancer and its treatment were that everybody who was having any symptoms of cancer should report immediately to a hospital for treatment. When we asked them about effect of cancer as a whole their responses were disturbed family role, disturbed relationship with family and friends, disturbed social role, financial burden as well as disturbed education respectively.

Conclusion: From this study we concluded that lived experiences of young adults diagnosed with cancer as challenging. It may also help to plan ahead by patients as well as health professional to improve the patient's quality of life.

Copy Right, IJAR, 2019,. All rights reserved.

\section{Introduction:-}

Non-communicable diseases are major health problem globally and cancer is a major health problem worldwide. Globally, cancer is a leading cause of death in $21^{\text {st }}$ century. ${ }^{1}$

Corresponding Author:-HassanMHMustafa.

Address:-Department of Nursing, All India Institute of Medical Sciences, Rishikesh. 
When we study cancer and its trend age wise, it was considered as disease of old age. But recent trend of different types of cancers showed that its rate is increasing in younger age group (20- 44 years) day by day. ${ }^{2}$ The population based cancer registry of international verses Indian data (2006-2008) and comparison of age adjusted rate (AAR) of all sites of cancer i.e. $\mathrm{C}_{00^{-}} \mathrm{C}_{97}$ showed that in male highest incidence occurs in brazil, i.e. in Goiania 631.9 per 100000 whereas in India incidence was highest in male in Kamrup urban district i.e. 206 per 100000. Where as in female again highest incidence was in Brazil, Goiania i.e. 474.6 per 100000 whereas in India incidence was highest in Kamrup urban district i.e. 174 per 100000. India's data (2006-2008) of Kamrup urban district showed that incidence of cancer in young age groups (20- 44 years) in male were 273 out of 1952 i.e. 13.99\% whereas in female it was 334 out of 1304 i.e. $25.61 \%$. $^{3}$

According to WHO, quality of life is defined as individual perception of life, values, objectives, standards and interests in the framework of the culture. Parson HM et al. (2012) conducted a study on impact of cancer on young cancer survivors. The results concluded that the future plan for work and school was negatively influenced by the cancer treatment and it led to quitting school or work. Majority of the patients reported problems with studies or work after the diagnosis of cancer. ${ }^{4}$ Cancer is strongly affecting quality of life of cancer patients. Thus more researches are required to explore areas which were affected from cancer diagnosis, treatment and palliative care.

When we study cancer burden on Indian economy then in year 2013 were 1086783 rupees, whether in year 2015 it increases to 1148692 rupees. ${ }^{5}$ The average out of pocket expenditure on inpatient service in the private sector is about three times that of the public sector. Also, treatment for about 40 percent of hospitalization for cancer cases is financially supported mainly through borrowings, contributions from friends and relatives and sale of assets. ${ }^{6}$

If we study how a female newly diagnosed with lymphoma at age 20 will ask following questions. Will it hurt? Will my hair fall down? Can I still go out with my friends? How will my life going to be change? These questions will be commonly asked when as a health personnel you will be in contact with newly diagnosed patient's that why we need to have in depth knowledge of cancer, information about treatment and effect of it on quality of life. Then only we can understand their problem and give them best possible solution for it.

Main focus of study was to explore lived experiences of the cancer patients who belong to young adult age group.

\section{Methods:-}

The study was conducted at All India Institute of Medical Sciences (AIIMS) Rishikesh in 2018. The written consent was taken from the participants of the study. Total 30 Participants were included in study. Ethical approval for the study was taken from Ethical Committee of Institute. Qualitative data were collected by using open ended questionnaire and data collection method was an interview.

\section{Results:-}

Table 1 showed qualitative data regarding patients' experience on the diagnosis of cancer. The subjects felt sad (9) on the diagnosis of cancer. Most of young adult cancer patients (23) preferred to disclose their diagnosis to their primary relatives. Majority of patients (17) were diagnosed with cancer in first stage and least patients (3) were diagnosed in $2^{\text {nd }}$ stage. Table 2 showed that most of the patient's personal life (12) as well as social life (15) were very much affected due to cancer.

Table 1:-Frequency and ranking of patients' experience on the diagnosis of cancer

\begin{tabular}{|l|l|l|l|}
\hline \multirow{3}{*}{$\begin{array}{l}\text { Q. } 1 \text { When patient is first } \\
\text { diagnosed as cancer, then } \\
\text { experience about cancer. }\end{array}$} & Options & f & Rank \\
\cline { 2 - 3 } & No effect & 3 & 4 \\
\cline { 2 - 4 } & Pain & 3 & 4 \\
\cline { 2 - 4 } & Sad & 9 & 1 \\
\cline { 2 - 4 } & Anxiety & 1 & 5 \\
\cline { 2 - 4 } & Fear & 1 & 5 \\
\cline { 2 - 4 } & Bit tension & 8 & 2 \\
\cline { 2 - 4 } $\begin{array}{l}\text { Q. 1 A. To whom they told } \\
\text { Canst about their diagnosis of }\end{array}$ & Lot of tension & 6 & 3 \\
\hline & Primary relative & 23 & 1 \\
\hline & Secondary relative & 5 & 3 \\
\hline Q. 1 B. At what stage your & Friend & 2 & 1 \\
\hline
\end{tabular}




\begin{tabular}{|l|l|l|l|}
\hline cancer were diagnosed? & Stage two level & 3 & 4 \\
\cline { 2 - 4 } & Stage three level & - & - \\
\cline { 2 - 4 } & Stage four level & 4 & 3 \\
\cline { 2 - 4 } & Not explained & 6 & 2 \\
\hline
\end{tabular}

The thematic analysis of data showed that subjects experienced psychological problem in the form of emotional turmoil (28) on the diagnosis of cancer.

As evidenced by following excerpts:

"I felt very bad, I thought how it happened to me? That was shocking"

"The information was painful, but I admitted the fact that I'm having cancer after confirming reports"

Table 2:-Frequency and ranking on effect of cancer on your personal and social life

\begin{tabular}{|l|l|l|l|}
\hline \multirow{3}{*}{$\begin{array}{l}\text { Q. } 2 \text { Effect of cancer in your } \\
\text { personal and social life? }\end{array}$} & Options & f & Rank \\
\cline { 2 - 4 } & No effect & 8 & 2 \\
\cline { 2 - 4 } a. On personal life & Affected & 2 & 5 \\
\cline { 2 - 4 } & Very much affected & 12 & 1 \\
\cline { 2 - 4 } & Work affected & 7 & 3 \\
\cline { 2 - 4 } & Work Role affected & 4 & 4 \\
\hline \multirow{3}{*}{ b. On social life } & No effect & 12 & 2 \\
\cline { 2 - 4 } & Affected & 3 & 3 \\
\cline { 2 - 4 } & Very much affected & 5 & 1 \\
\hline
\end{tabular}

The participants' personal and family life got affected due to cancer. Some of the subjects verbalized no effect in life due to cancer. In personal life, the effects were in physical, psychological, social and economic domains. In physical domain, the effects were role alteration in daily life (11 responses), change in dietary pattern (1 response), and sideeffects of chemotherapy (3 responses).

The verbalizations of participants were as follows:

"I can't go to school, and I feel self-pity"

"I experience change in food intake and ability to work"

"Swelling and pain occurred due to cancer treatment"

In psychological domain, emotional turmoil (9 responses) experienced by the subjects and it is evidenced by the following comment:

"We all were scared, now I think that it may get cured"

In the case of social domain, the participants faced problems like disturbed family life ( 3 responses), discontinuation of education (3 responses) and homebound (1 response).

As expressed in following excerpts:

"I became unable to take care of children"

"I quitted my study"

"I can't go to college"

"I became unable to meet others"

In economic domain, the participants faced financial hardship ( 2 responses) as evidenced by the following comment: "My financial status became poor"

Some of the participants expressed no change in their social life (6 responses).

One subject expressed improved social relationship during the continuum of cancer and verbalized "Now I am in good relationship with others".

One subject was expressed that the hospital environment is uncomfortable. 
Some of the participants expressed changed social relationship ( 8 responses) during the trajectory of cancer.

As evidenced by following excerpts:

"My friends and relatives left me, they are not giving support"

"Relatives do not meet me nowadays"

Table 3:-Frequency and ranking of helpful activity during diagnosis and treatment of cancer

\begin{tabular}{|l|l|l|l|}
\hline \multirow{4}{*}{$\begin{array}{l}\text { Q. 3. Activity helpful } \\
\text { during diagnosis and } \\
\text { treatment of cancer }\end{array}$} & Options & f & Rank \\
\cline { 2 - 4 } & No Help & 11 & 1 \\
\cline { 2 - 4 } & Family & 8 & 3 \\
\cline { 2 - 4 } & Friends & 2 & 4 \\
\cline { 2 - 4 } & Doctor & 10 & 2 \\
\cline { 2 - 4 } $\begin{array}{l}\text { Q.3 A. Cancer treatment } \\
\text { options after diagnosis }\end{array}$ & Chemotherapy & 1 & 5 \\
\cline { 2 - 4 } & Surgery & 22 & 1 \\
\cline { 2 - 4 } & Radiotherapy & 11 & 2 \\
\hline $\begin{array}{l}\text { Q. 3 B How was the } \\
\text { treatment of cancer }\end{array}$ & Chemotherapy & 19 & 2 \\
\cline { 2 - 4 } & Surgery & 10 & 3 \\
\cline { 2 - 4 } & Radiotherapy & 4 & 1 \\
\hline
\end{tabular}

Table 3 depicted the helpful activity for cancer patients during diagnosis and treatment of cancer. The responses were more about lack of support from others (11 responses) i.e. no one helps them when they were diagnosed and treated for cancer. Cancer treatment options after diagnosis were chemotherapy (22), and majority of cancer patients treatment were going with chemotherapy (19) only.

Some of the responses of subjects were as follows:

"The attitude and advice of doctor was very helpful during this period"

"My family was very supportive"

"My friends and relatives stood by my side during this period of illness"

"Prayers of my wife and sister were very helpful"

"I found relief in religious rituals"

Table 4:-Frequency and ranking of difficulties faced during diagnosis and treatment

\begin{tabular}{|c|c|c|c|}
\hline \multirow{5}{*}{$\begin{array}{l}\text { Q. } 4 \text { Difficulties } \\
\text { during diagnosis } \\
\text { treatment? }\end{array}$} & Options & $\mathbf{F}$ & Rank \\
\hline & No effect & 4 & 3 \\
\hline & Physical Difficulty & 3 & 4 \\
\hline & Work Role difficulty & 6 & 2 \\
\hline & Transport/ Convenience & 2 & 5 \\
\hline a. During Diagnosis & Financial difficulty & 21 & 1 \\
\hline \multirow{5}{*}{ b. During Treatment } & No effect & 1 & 4 \\
\hline & Physical Difficulty & 10 & 1 \\
\hline & Work Role & 6 & 2 \\
\hline & Financial Difficulty & 10 & 1 \\
\hline & Care difficulty & 2 & 3 \\
\hline
\end{tabular}

Table 4 depicted that young adult cancer patients most common difficulties faced during diagnosis of cancer were financial difficulties (21) and during their treatment difficulties faced were physical (10) as well as financial (10) difficulties.

Thematic analysis of qualitative data revealed the following themes:

In physical domain, role alteration in daily life (12 responses), side-effects of chemotherapy (7 responses), difficulty in travelling ( 2 responses), and difficulty in finding donors (1 response) were the difficulties.

The excerpts were as follows: 
"I became unable to work"

"I am experiencing pain nowadays"

"I am facing problems in travelling"

"I find it difficult to get donors for replacement of blood"

In the case of difficulty in psychological domain, some subjects revealed emotional turmoil (4 responses). As evidenced by the comment:

"My family members are in tension due to my disease"

As per difficulties in social domain, the issues were disturbed family life (5 responses), lack of caregivers (1 response) and disturbed social life (2 responses). Cancer also affected their financial status and the responses were more in number (19 responses).

As expressed in following excerpts:

"Because of the disease my children's education discontinued"

"There is no one to look after me"

"I have problems in social relationship"

"I am facing financial difficulty"

Table 5:-Frequency and ranking of other opinion in cancer and its diagnosis

\begin{tabular}{|c|c|c|c|}
\hline \multirow{5}{*}{$\begin{array}{l}\text { Q. } 5 \text { In cancer and } \\
\text { its diagnosis, what } \\
\text { were other } \\
\text { opinion }\end{array}$} & Options & $\mathbf{F}$ & Rank \\
\hline & Immediate treatment at hospital & 22 & 1 \\
\hline & No use of treatment & 3 & 3 \\
\hline & Referral for another hospital/ doctor & 4 & 2 \\
\hline & Alternative treatment & 1 & 4 \\
\hline
\end{tabular}

Table 5 depicted that young adult cancer patient's opinion for cancer and its treatment. The results concluded that they opine immediate reporting to hospital for treatment (22).

Table 6:-Frequency and ranking of effect of cancer as a whole

\begin{tabular}{|c|c|c|c|}
\hline & & & \\
\hline & Options & $\mathbf{F}$ & Rank \\
\hline & No formal change & 3 & 4 \\
\hline & Financial burden & 3 & 4 \\
\hline & Family role disturbed & 8 & 1 \\
\hline Q. 6 Effect of & Physical health disturbed & 5 & 2 \\
\hline cancer as a Whole & Nutritional disturbed & 1 & 5 \\
\hline & Social role disturbed & 4 & 3 \\
\hline & Educational disturbed & 1 & 5 \\
\hline & Attachment with family \& friends & 5 & 2 \\
\hline
\end{tabular}

Table 6 depicted the effect of cancer on young adult life as a whole were disturbed family role (8), followed by disturbed attachment with family and friends (5), whereas no formal change (4) followed by least effect were on disturbed nutritional (1) as well as disturbed education (1) after having cancer diagnosis in young adult age groups. Thematic analysis concluded the following results. As per effect of cancer in physical domain, the participants expressed the negative effects in physical, psychological, social and economic domains. Some responses were of good effects in life due to cancer.

In physical domain, the effects were side-effects of treatment (3 responses), role alteration in daily life ( 9 responses), and changed dietary pattern (1 response).

The responses were evidenced by following excerpts:

"I became unable to work and feel weakness"

"I became restricted in food intake" 
In psychological domain, the subjects experienced emotional turmoil and change in behavior due to cancer (5 responses).

As expressed by subjects:

"I feel it (cancer) like a storm"

"It is a sad condition"

In social domain, the effects were disturbed social relationships (1 response), discontinued education (3responses) and a state of homebound (4 responses).

As evidenced by following excerpts:

"I was rejected by my friends and relatives"

"I can't go outside for a walk with my friends"

"I feel to be bound in chain"

"My study discontinued"

"I am not going to school since last two years"

In economic domain, the subjects experienced financial hardship (3 responses) during the continuum of cancer.

As verbalized by one subject:

"My life became in trouble due to financial difficulty"

\section{Discussion:-}

Qualitative data of the study also revealed that when patient were first diagnosed about cancer, they feel were sad (9) and most of young adult cancer patients (23) preferred to told about their diagnosis to their primary relatives and many of patients (17) cancer were diagnosed in first stage (17) of cancer. When young adult cancer patients were asked about effect of cancer on their life, they expressed change in personal life (12) and in social life (15). Most of the subjects expressed absence of help from others during diagnosis and treatment of cancer (11). Cancer treatment options after diagnosis were chemotherapy (22), and majority of cancer patients treatment were going with chemotherapy (19) only. Most common difficulty faced by young adult cancer patients during diagnosis of cancer was financial difficulty (21). Young adult cancer patient's opinion for cancer and its treatment was immediate treatment at hospital (22). Effect of cancer on young adult life as a whole were disturbed family role (8), disturbed attachment with family and friends (5), disturbed social role (4), financial burden (4) as well as disturbed education (1) after having cancer diagnosis in young adult age groups.

\section{Conclusion:-}

The most common life experience that every cancer patient comes across was an economic stabilization. Economic condition which is required for their treatment and family needs to be fulfilled. The prognosis of disease according to the stage of the diagnosed disease needs to be explained well in advance. As a healthcare professional never hesitate to discuss important concept of economic handling. Never focus only on treatment and prognosis part. By discussing various opportunity and options the anxiety of patient will be reduced and which helpful for effect of treatment also. In discussing economic burden to patient alone can be stressful. The environment of family gives an enough understanding about treatment choice and economic role shifting of another person of a family. This communication helps effective treatment options. Every individual diagnosed and enroll for treatment to give importance in each discussion part of their treatment options and family commitments. This will improve their health related quality of life of a patient. Every individual member of a health care team should equally participate in treatment options. To achieve quality of life, individual has to be acknowledged in each care activity given to him.

Knowledge gained from this study could be useful for in depth understanding of common problems faced by young adult cancer patients. It may also help to plan ahead by patients as well as health professional to improve quality of life.

\section{Financial support and sponsorship \\ Nil}

\section{Conflicts interest}

There are no conflicts of interest. 


\section{References:-}

1. Freddie Bray, Jacques Ferley, Isabelle Soerjomataram, Rebecca L. Siegel, Lindsey A. Torre, AhmedinJemal. Global Cancer statistics 2018: GLOBOCAN estimates of Incidence and Mortality worldwide for 36 cancers in 185 countries. A Cancer Journal of Clinicians .2018; 0: 1-31.

2. D Sharma, G Singh. Spectrum of cancer in adolescents and young adult: An epidemiological and clinicopathological evaluation. Indian Journal of Cancer. 2016; 53 (3): 457- 459.

3. Jagannath Dev Sharma, Amal Chandra Kataki, Debanjana Barman, Arpita Sharma, ManojKalita. Cancer statistics in Kamrupurban district: Incidence and mortality in 2007-2011. Indian journal of cancer .2016; 53 (4): 600-606.

4. Parsons HM, Harlan LC, Lynch CF, Hamilton AS, Wu XC, Kato I, Schwartz SM, Smith AW, Keel G, Keegan TH. Impact of cancer on work and education among adolescent and young adult cancer survivors. Journal of Clinical Oncology. 2012 Jul 1;30(19):2393.

5. Three year report of population based cancer registries: Incidence, distribution, trends in incidence rates and projections of burden of cancer. National cancer registry programme: Indian Council of Medical Research. Bengaluru, India. March 2016.

6. Rajpal S, Kumar A, Joe W. Economic burden of cancer in India: Evidence from cross-sectional nationally representative household survey, 2014. PloS one. 2018 Feb 26;13(2):e0193320. 